\title{
How Artificial Intelligence Transforms the Experience of Employees
}

\author{
Sobia Wassan ${ }^{1}$, Dr. Kamal Gulati ${ }^{2}$, Harikumar Pallathadka ${ }^{3}$, Beenish Suhail ${ }^{4}$, Preeti \\ Kuhar $^{5}$, Ankur Gupta ${ }^{6}$ \\ ${ }^{1} \mathrm{Ph} . \mathrm{D}$. Scholar, Nanjing University, Jiangsu, China \\ ${ }^{2}$ Associate Professor, Amity University, Noida, Uttar Pradesh, India | \\ Independent Consultant, Stratford University, Virginia, USA \\ ${ }^{3}$ Director, Manipur International University, Imphal, Manipur, India \\ ${ }^{4}$ Ph.D. Scholar, School of Economics, Shanghai university, Shanghai 200444,China \\ ${ }^{5}$ Assistant Professor, Department of Civil Engineering, Faculty of Engineering and Technology, \\ SGT University, Gurugram, Haryana, India \\ ${ }^{6}$ Assistant Professor, Dept. of Computer Science and Engineering, Vaish College of Engineering, \\ Rohtak, Haryana, India
}

Sobia Wassan(sobiaali614@gmail.com)

Dr. Kamal Gulati (drkamalgulati@gmail.com)

Harikumar Pallathadka(harikumar@miu.edu.in)

Binish Suhail(binish.wasan@gmail.com)

Preeti Kuhar(preetikuhar555@gmail.com)

Ankur Gupta(ankurdujana@gmail.com)

Corresponding Author: Dr. Kamal Gulati, Associate Professor, Amity University, Noida, Uttar Pradesh, India $\mid$ Independent Consultant, Stratford University, Virginia, USA, drkamalgulati@gmail.com

Article History: Received: 10 January 2021; Revised: 12 February 2021; Accepted: 27 March 2021; Published online: 28 April 2021

\begin{abstract}
Artificial intelligence brings large markets, including advertising, tourism, finance, policy, workplace education. We probably associated with Chabot's job (defined as an automated, but personalized, a conversation between software and human users). We plan to use Chatbots in the workplace to assist us in pursuing a new career, addressing human resource questions, and also accepting coaching and mentoring after using them further in our personal lives. Since Chabot digitizes human resource programs, workers can access HR solutions from anywhere. HR artificial intelligence can result in a more streamlined, scalable and user-driven employee interface. To find the convergence between artificial intelligence and human resources, HR executives started using Chatbots in recruiting, staff service, staff production, and preparing to create greater value for the company. Indeed, Chabot's can be treated as the HR team's newest participant, capable of quickly finding solutions to commonly asked questions. Since we've grown accustomed to Chabot's in our everyday lives, we intend to use them at work. Artificial intelligence is changing how career
\end{abstract}


applicants and workers interact. Five operational procedures are supposed to kick-start this new transformation when managers begin to implement artificial intelligence plans and roadmaps: 1 . Experiment with different Chatbots to learn artificial intelligence. 2.Develop a joint strategy for HR, IT, Real Estate, Communitarians and Digital Transformation cross-functional partners; 3. Recognize how deployment can affect the technology roadmap; 4 Identify new job tasks that will make full usage of AI in HR; 5 Improve the understanding of artificial intelligence in the workplace by the HR team.

Keywords: Chabot, Artificial Intelligent, Human Resource, Employee, Transform, HR skill

\section{Introduction}

At home and at work, artificial intelligence is changing our lives. Already, 1.8 million users use Amazon's Alexa to monitor their lighting and unlock their cars at home, and Alexa is said to have over 3,000 skills and is rising on a regular basis. This is incredible. Artificial intelligence is now emerging in the workplace as an intuitive companion to make us work better. Artificial intelligence isn't the workplace's future; it's already now, and it's occurring now.

HR leaders are beginning to test catboats to improve the employee experience, just as advertisers have learned the ability of catboats to personalize a buying experience. In reality, AI investments increased by 746 percent in five years, from $\$ 282$ million in 2011 to $\$ 2.4$ billion in 2015 . In 2016, more than $\$ 1.5$ billion was invested in more than 200 AI-focused firms, bringing the total to over $\$ 2$ billion. This pattern does not seem to be slowing down anytime soon. "Artificial Intelligence is the study of the computations that make it possible to perceive, reason, and act." (Winston, P. H. 1992). "Intelligence is the capability of a system to adapt its behavior to meet its goals in a range of environments." (Fogell, D. B. 2006). Formal definition: "Intelligence measures an agent's ability to achieve goals in a wide range of environments." General definition: "A very general and flexible capacity to succeed when faced with a wide range of problems and situations." (Legg, S. and Hotter, M. 2007). "The computational aspect of the capacity to accomplish targets in the universe is intelligence." (McCarthy, J., and the Formal Reasoning Group at Stanford University, 2017) "The essence of intelligence is the principle of adapting to the environment while working with insufficient knowledge and resources," said P. Wang in 2008. As a consequence, an intelligent machine can focus on limited computing power, run in real time, be adaptable to new challenges, and learn from its mistakes. "Intelligence" is defined as a kind of "relative rationality" in this working definition. General definition: "Intelligence is the capacity of a system to adapt to its environment while operating with insufficient knowledge and resources." Laird, J. E., Wray, R. E., Mariner, R. P., and Langley, P. 2009 said, "The goal is to build computer systems that exhibit the full range of the cognitive capabilities we find in humans. The ability to pursue tasks across a broad range of domains, in complex physical and social environments. [A human-level intelligence] system needs broad competence. It needs to successfully work on a wide variety of problems, using different types of knowledge and learning in different situations, but it does not need to generate optimal behavior." Gentzel, B.2010 said "Pragmatic general intelligence measures the capability of an agent to achieve goals in environments, relative to prior distributions over the goal and environment space. Efficient pragmatic general bits of intelligence measure this same 
capability, but normalized by the number of computational resources utilized in the course of the goal-achievement." Nilsson, N. J.2010 said, "Artificial intelligence is that activity devoted to making machines intelligent, and intelligence is that quality that enables an entity to function appropriately and with foresight in its environment." Russell, S. J., and Nerving, P. 2010said, Formal definition: "Intelligence is concerned mainly with rational action. Ideally, an intelligent agent takes the best possible action in a situation." General definition: "The designing and building of intelligent agents that receive percepts from the environment and take actions that affect that environment." Four possible goals: "systems that think like humans, systems that act like humans, Systems that think rationally, Systems that act rationally." "Intelligence measures an agent's capacity for efficient cross domain optimization of the world according to the agent's preferences." (Muehlhauser, L. and Salmon, A.2012). "Machines matching humans in general intelligence that is, possessing common sense and an effective ability to learn, reason, and plan to meet complex information- processing challenges across a wide range of natural and abstract domains." (Bistro, N. 2014). Gershan, S. J., Horvitz, E. J., and Tenenbaum, J. B. 2015 said, "e charts the view of intelligence as computational rationality: computing with representations, algorithms, and architectures designed to approximate decisions with the highest expected utility while taking into account the costs of computation." "A central goal of general artificial intelligence [is to] create a single algorithm that would be able to develop a wide range of competencies on a varied range of challenging tasks." (Minho, V. et al. 2015). Emma, et al.2016 said, AI is defined as

"intellectual machines and systems that could automatically sense people's situations or expectations, and offer necessary information before it is required." Formal definition: "Artificial intelligence, the capability of computer systems to perform tasks that normally require human intelligence (e.g., perception, conversation, decision- making)." General definition: "AI systems will provide the most added value (the competitive edge), not only by equating human intelligence but precisely by surpassing it - even if only within a narrow domain, such as information analysis or reaction time." [the United States Defense Science Board (DSB) 2017].

"One strategically (and therefore analytically) relevant definition for our purposes is that of AI as a rational optimization agent that can (enable humans to) act competently in the world (that is, subtype Behavior and Rational)." (De Spiegel Eire, S., Maas, M., and Swains, T. 2017). Formal definition: "Machine Intelligence is the ability of a 'bounded optimal' agent to provide rational, unbiased guidance and service to humans so as to help them achieve optimal outcomes in a range of circumstances." General definition: "Machine Intelligence (MI) is the continuation of intelligence by an artificial agent in support of humanity." (Lewis, C. W. P. and Monett, D. FORTHCOMING) Intelligence means the organizing of concepts, as well as the complex interconnection of all such ideas that must be grouped together due to the natural relationships between the empirical evidence they reflect. The identification of a physical rule in a slew of apparently irrelevant phenomena, or the analysis of a historical occurrence about which only a few facts are directly understood, are examples of wisdom reasoning that considers a plethora of interactions that the less intelligent mind might overlook. The cornerstone of knowledge is a union of memory and attention, not memory or attention alone." (Ebbinghaus, H.1908). "Intelligence serves in the discovery of truth. But the conception is still too narrow; and we return to our favorite theory; the intelligence marks itself by the best possible adaptation of the individual to his environment." (Binet, A. and Simon, T.1909). Wechsler, D. 1939 said, "Intelligence is the aggregate or global capacity of the individual to act purposefully, to think rationally and to deal effectively with his environment. It is global because it characterizes the individual's behavior as 
a whole; it is an aggregate because it is composed of elements or abilities which, though not entirely independent, are qualitatively differentiable." Bigge, M. L. 1976 said , "Intelligence is an individual's ability to respond to a given situation by anticipating the possible consequences of his actions." Humphreys, L. G. 1984 said , Intelligence is an individual's "entire repertoire of acquired skills, knowledge, learning sets, and generalization tendencies considered intellectual in nature (problem solving skills) that [is] available at any one period of time." Anastasi, A. 1986 said, "Intelligence is a conduct performance. In so far as because it reflects appropriate means of satisfying the demands of an evolving world, intelligent behavior is fundamentally adaptive." "Intelligence, as the sum total of all cognitive processes, entails preparation, coding of information, and attention arousal," said J. P. Das in 1986. The cognitive processes used for planning have a higher standing of intellect than the others. Planning is a general concept that encompasses the creation of plans and goals, the collection of available plans, and the implementation of such plans, among other aspects. The terms "coding" and "sequential coding" correspond to two different ways of accessing data. The final step (attention arousal) is fundamental to all other higher cognitive functions." "Intelligence is mental self-government," said R. J. Sternberg in 1986. The purpose of intelligence is that it allows us to control ourselves in such a way that our thoughts and behaviors are ordered, cohesive, and attentive to both our internal and external needs." Fontana, D.1988 said, "[Intelligence is] the ability to see relationships and to use this ability to solve problems." Gottfredson, L. S. 1997 said, "Intelligence is a broad term that encompasses the capacity to reason, prepare, solve problems, think abstractly, comprehend complicated concepts, learn easily, and learn from experience, among other things. It's not just about book learning, a specific intellectual ability, or test-taking prowess. Rather, it reflects a greater and stronger ability to comprehend our surroundings — the ability to "catch on," "make sense," or "figure out" what to do. Ramos-Ford, V. and Gardner, H.1997 said, " "[ntelligence is] an ability or set of abilities that permit an individual to solve problems or fashion products that are of consequence in a particular cultural setting." Simonton, D. K.2017 said , "My view of intelligence is basically a Darwinian one. It's based on sort of the old Functionalist notion that goes way back to Francis Galton, that says that there are a certain set of cognitive capacities that enable an individual to adapt and thrive in any given environment they find themselves in, and those cognitive capacities include things like memory and retrieval, and problem solving and so forth. There's a cluster of cognitive abilities that lead to successful adaptation to a wide range of environments." Sternberg, R. J. 2005 said, "Intelligence is: 1) the ability to achieve one's goals in life, given one's sociocultural context; 2) by capitalizing on strengths and correcting or compensating for weaknesses; 3 ) in order to adapt to, shape, and select environments; and, 4) through a combination of analytical, creative, and practical abilities." "Intelligence is clearly a combination of the ability to "figure things out on the spot' and the ability to retain and repeat things that have been figured out in the past." (Deary, I. J., Penke, L., and Johnson, W. 2010). Hampshire, A. et al. 2012 said , "Human intelligence is most parsimoniously conceived of as an emergent property of multiple specialized brain systems, each of which has its own capacity that contribute to an individual's ability to perform across a broad range of cognitive tasks." Stanovich, K. E. 2014 said, to think and behave "rationally means taking the appropriate action given one's goals and beliefs and holding beliefs that are commensurate with available evidence." Intelligence is thus: "optimal behavior in the domain of practical affairs. The optimization of the individual's goal fulfillment." "Intelligence is associated with important economic and health related life outcomes." (Sniekers, S. et al. 2017). Artificial 
intelligence is moving from health care to the advertisement, transportation, finance, law, education, and now every major industry in the workplace. Many of us could have had a Chabot (defined as an automatic, yet customized, program and the conversation between human users) contact, whether it was via Facebook Messenger for hotel reservations, 1-800 fresh flowers, or orders. Facebook Messenger chat app currently has over 100000 robots, according to Facebook Vice President David Marcus. Compared with 33000 in 2016.The first year, the Messenger platform Facebook Messenger developers have created 100000 robots of the Messenger. In developing products for the

Facebook platform developer's conference's F8 conference last keynote, Vice President David Marcus (David Marcus) issued a statement. "Now, we will be business and user information between doubled, article 2 billion per month, there are more than 100000 robot's platform. This number is higher than last year in September, 33000.It's crazy, "said Marcus. In 2016, on F8 platform released the first Messenger platform, to allow businesses and third-party developers to create their own robot Today marks the launch of Messenger App 2.0, which will feature chat plugins, a TAB devoted to exploring robotics and local businesses, and personalized integration close to Delivery.com. Release as Facebook Messenger's advice, billions of people for the first time tasted the social media company assistant "artificial intelligence" .On Tuesday, Facebook would have a thing to a new level, display that it is running a pilot, to see whether the third party apps will interact with M, the first partner is Delivery.com. For anyone in the United States Delivery.com services industry, the integration would impact the Al, to determine when in discussion will be suggested by the right period for the food. Facebook Messenger product owner Stan Chudnovsky said: "if you choose to order a pizza, much as you do in the Messenger stickers, place and payment, you can get an interface, you can pick what you want pizza.

"Nature, the longer you use chat application request of food, the more the $\mathrm{M}$ would be more and more knowledgeable, it could be of interest to you. He cautioned that this is only an examination, "so we don't know where it would go. "We don't know whether someone will do it. However, he said, with the passing of time, the third party experience can reach Facebook "infrastructure". Eating is a kind of social events, thus, the collocation of Delivery.com and Facebook Messenger is not astonishing. If you're in a big party, you would want to know where to go for lunch, dinner, snacks, or just a snack. Though outdoor activities are popular, there are times when remaining at home is preferred, such as for movie night, study groups, or other purposes. Combined communities on the Messenger just introduced payment, do you have all the stuff you need to take care of a vital part of the night. While Facebook Delivery.com can be attached to the chat Messenger extension, via direct it with $\mathrm{M}$ integration, it is anticipated it can support you that do more with less effort. Today's announcement is posted, along with other Messenger network upgrade, since Facebook will be attending to support users locate the company on chat application and bot. We expect to use the bot in the office support us pursue a new job, address human resources queries, and even accept counseling mentoring as we extend our use of both in their personal lives. Employees would be able access HR solutions from anywhere with the help of a bot. Artificial human resource intelligence will result in a more seamless experience, one more flexible and user-

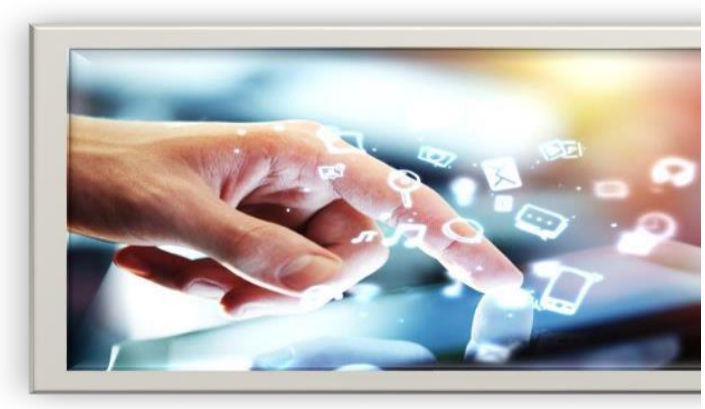

and to 
driven. One factor a slew of buyer brands incorporate AI into their goods is for the sake of velocity. About $22 \%$ of millennials think they will expect an answer within 10 minutes of contacting a buyer brand. The solution: buyer brands rapidly switch to catboats to provide round-the-clock service, connect easily with buyers, and react to their requests. For example, Staples utilizes deep learning to automate shopping and customer care, connecting with customers in real time through their Facebook Messenger app..

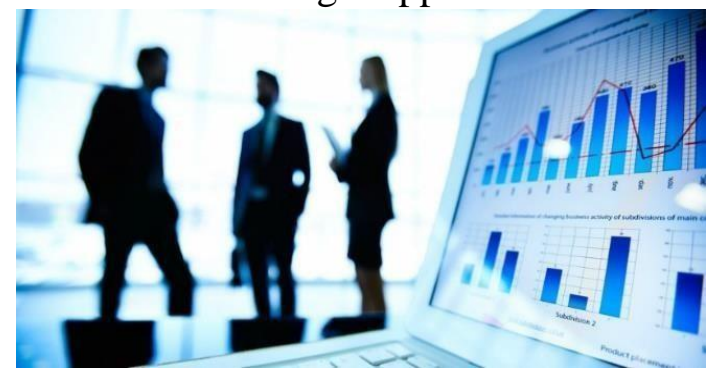

Instant answers aren't all for millennials. We've also been digital customers: in 2016, Gartner estimated that approximately $\$ 2$ billion in internet transactions were completed solely by mobile digital assistants. Is it now a must-have artificial intelligence (AI)? Is it not possible to hire intelligent employees in the fields of recruitment, HR services, and learning and development? Wow, the conclusion seems to be yes! HR leaders need to start experimenting with all facets of AI in order to bring value to their organizations. As intelligent helpers become more common in our personal lives, we can expect to see them even at work. Employees profit from catboats because they receive superior service efficiency, from real-time replies to HR requests to tailored learning and development. In addition, they are important for the 3.7 million workers or $2.8 \%$ of the employees who operate at least in part-time remotely and who have little easy connection to HR. Catboat are suitable for maximizing the talent acquisition and onboarding processes of HR managers by increasing speed and precision in responding to the frequently asked questions of HR. Consider Jane, a 2014 Loka-built Chabot. In real time Jane answers a number of HR issues, such as "Looking forward to President's Day?" Jane will answer any queries or questions in a folder which can be stored. The other advantage of Jane is that it can track employee issues using realtime technologies and then utilize sentimentality analysis to fix them. Assume that the majority of employees are investigating late travel settlement charges. This detail may suggest that everything about the framework doesn't work properly. HR representatives can announce the issue and communicate a plan before a full-fledged problem arises. Certainly, Jane cannot deal with any questions at this moment, but it is now possible to have AI in your HR service center with all the kinds of HR-related questions.

\section{The Employee Experience Can Be Transformed by Artificial Intelligence}

Artificial intelligence is transforming our personal and professional lives. You may be using Amazon Alexa at home to power your lights, unlock your engine, and get your portfolio companies in 1.8 million one of the most recent stock quotes. Alexa boasted that she has over 3000 different talents and that this number is rising every day. Artificial intelligence is emerging in the workplace to become an insightful companion to make us work smarter. Artificial intelligence is not the workplace of the future; it is the workplace of the present. The intelligent assistant, also known as a bot, or programmed to mimic human dialogue, is being pursued by IBM and a slew of start-ups. 
If it's a human resources query or a computer algorithm for a customized learning experience, A survey of approximately 400 chief human resources officers by the Institute of IBM Business Value (IBM Institute for Business Value) finds that half of the sample were using cognitive processing capacity to change core aspects of human resources, such as human resources operations, talent selection, and talent creation. As marketing researchers found that the strength of the bot to the personalized shopping experience, hr leaders are beginning to try bot to change employees experience. Al investment grew from \$2011 in 282 million to \$2015 in 2.4 billion, the growth of $746 \%$ in five years. In 2016, this number continues to grow, in 2016, more than 200 key AI centered in the company invested about $\$ 1.5$ billion.

Al Landscape: Global Yearly Financing History $2011-2015$

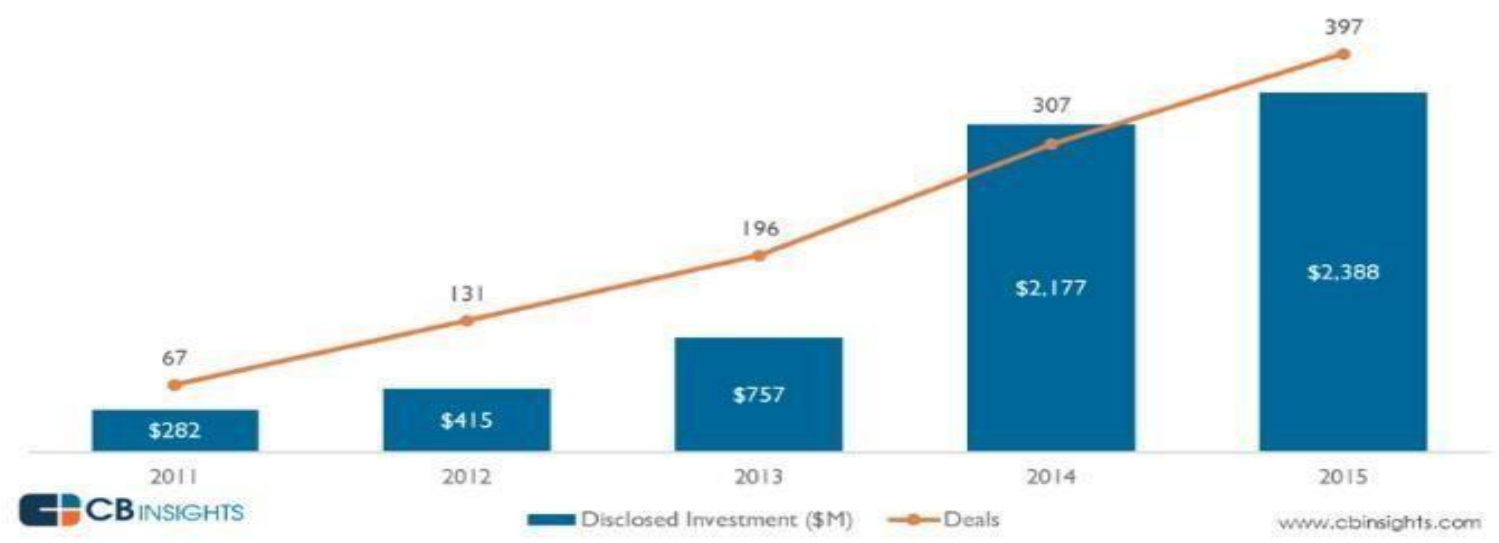

Contiguity is numerous consumer brands in their products to establish a cause of AI. According to the Desk.com survey, more than $23 \%$ of millennials want to find a consumer brand in 10 minute. Solution: consumer brands are increasingly turning to bot, provide $24 \mathrm{x} 7$ services, Interacting with consumers easily and answering their questions staples, etc. Machine learning, for example, is now being used to simplify order and customer service processes., and through their Facebook Messenger application to attract customers in real time. But not only the millennials want an immediate answer. We all become the digital consumer. In 2017 is expected to become a network session to experience the decisive year. According to Gartner, a consulting firm (Gartner), according to data from 2016, mobile digital assistant online sales of nearly \$2 billion. IBM USES Watson (Watson) to transmute health care. Watson can treat a rare childhood disease, Kidney disease in children under the age of two, for example. Watson can read any of the medical literature, and the quick link mode allows physicians to make smarter patient decisions. Perhaps this is why Bernard j. Tyson, the CEO of Kaiser Permanente, is so concerned. "I don't think any physicians should be today in the absence of artificial intelligence in practice," (Bernard j. Tyson) said. It's difficult to detect patterns or developments in other situations, let alone observe and nurse them. 
Human resources in the workplace, chief executive of the use of artificial intelligence, we can say the same thing? Will we think that does not use an intelligent assistant to change recruitment, human resources service center, learning, and development are inconceivable? Yes, I think the answer is. In order to provide importance to their organisation, human resources executives must begin attempting to address all facets of the Al. We expect to see a similar use of intelligent assistants in the office as the role of intelligent assistants becomes more commonly used in our lives. For workers, though, it offers an unrivaled employee experience, ranging from the human resource dilemma of real-time response to customized learning and growth. Furthermore, they make up about 3.7 million employees, or 2.8 percent of the population, and they work at least most of the time from home, but it is difficult to get into the human resources department. For human resources leaders, the bot is ideal for enhancing the talent selection and induction process by increasing pace and providing greater consistency, as well as responding to common human resources challenges by improving the talent acquisition process and improving online learning experience and providing greater consistency.

\section{Chatbot's will respond to often asked questions from employees.}

Let's take a look at 2014 founded by Locke bot Jane. Jane offers a series of HR issues real-time response, including "we are in the President's take the day off? "What is the dental benefits "or" I?" Jane is capable of answering any email, and her responses can be saved in the archive. In comparison to the most general inquiries, , chief executive of bobby Pranab Mukherjee says Jane for those they might not know is the purpose of actively promoting the welfare of employees.

"The corporation is promising a lot of new welfare," Mukherjee said, "but they have no successful means to encourage its use." Consider Jane's ability to reach workers. "Hey, John, how are you today at 3 o 'clock in the afternoon in your building tried our yoga class? Click here to register your own automatically. You have been working hard, your worth it!" Jane another value analysis is the use of real-time tracking problem employees, then apply sentiment analysis to solve these problems. Assuming that most employees are asking questions about the late payment of travel expenses. These data can show some things don't work properly in the system. Before things become a complete problem, hr leaders can find problems and communication solutions. Jane can't answer this question, of course, but the opportunity to provide HR related issues for AI, these problems may appear in your HR service center.

\section{To Improve Chabot's Talent Acquisition}

Talent acquisition and new hire orientation are the mature areas, in these areas, an intelligent assistant can use multiple data sources to develop candidate data chart, interview arrangement, and the applicant to make a decision about the future. Talla is a bot, it is designed to increase job candidates for HR process. Talla can offer a series of interview questions, according to the character can even recommended value net investigation after the hiring process. Talla, chief executive Rob May think, "an intelligent assistant can increase the middle human resources experts work, so she could concentrate on the more important human resources issues. "The vision is behind the startup Talla, how will they eventually become human resources experts provide resources and orientation for new employee's consultant in real time. May reckons that Talla in recruitment and induction training for new employees to save a lot of time, and will greatly 
improve the staff's working experience. Improve the talent acquisition and new hire orientation is Chris's top priority.IBM business value, research director at the Institute of Eric Lesser said: "more than half of the respondents CHROs believes that cognitive computing will influence the broad role of human resource organization, from senior management to the personal service center."

\section{Chabot's As Education Supporters}

Professors of the online school, which are known as MOOCs (massive open online courses), are guiding a late application of intelligent assistant professor. By the end of 2015, the number of students enrolled in MOOCs had risen dramatically. 35 million people signed up for, and the number of the previous year to 1600-18 million, university professor and assistant work also more and more. Type Gil Watson's name, so named, because IBM Watson analysis provides it. Jill is the Technology Institute of Georgia, Ashok, an online lecturer, one of 9 teacher assistants for over 300 learners, called 'artificial intelligence knowledge.' Professor Goel reports that this course has opened online BBS on about 10,000 student questions since 2014. In 2016, a professor introduced Jill Watson, a new teacher, to provide students with quicker response and input. Goel predicted that Professor Jill Watson could address $40 \%$ of students within a year so that the human task could resolve more complicated technological or conceptual issues such as "How do you describe intelligence?" In reality, one student said: "just as I want to appoint Gil Watson as a good teaching assistant, she always reminds us to have the right date and issued some questions in the week, I find to have a huge surprise when she was a bot." Intelligent assistant such as Jill Watson can be used as MOOCs and SPOCs (small private online courses) to expand the position of human education assistant. Professor emphasized that Jill Watson teaching was completed at an expert stage, her morale rate hit 97 percent at least. Ed Miller, NovoEd saw Al's Chief Executive Officer, today we dream of the strength of information. Miller said, "Artificial intelligence will make personalized learning easier for people to adapt to the learner experience." This would impact all facets of human resources and not just the enterprise's learning capacity, but the human resources core and the retention of talent. The members of the HR team need to learn more about the bot and how to experiment with it to improve the working experience of the employee. Human resources executives started utilizing the bot to provide the organisation with greater utility in terms of recruiting, personnel services, personnel growth and training. Service Now on 350 HR leaders in recently, a poll has found 92 percent of the director of human resources, provide higher level support personnel would have talk robot in the future. You can also put the bot as your most recent HR team members, allowing employees to find answers to common questions easily. According to a survey conducted by Service Now, more than two-thirds of managers think workers will easily access the bot and have access to the details they need when necessary. HR representatives think that employers in all cases should take a challenge from a secular and realistic viewpoint; for example, how much compensated holidays are to more private employees; for example, the nature of sexual assault. Figure 1 shows $\mathrm{Al}$ for the convenience of the question workers. 
Figure 1 Two-thirds of HR leaders believe employees are very comfortable using chatbots to interact on factual/transactional inquiries

\section{Employee Comfort Levels}

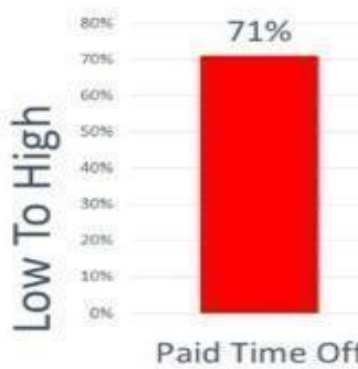

O Furure workplace $14 \mathrm{C}$, $201 \%$

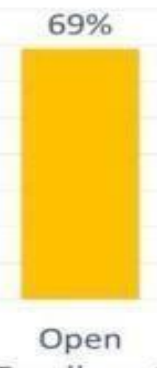

Enrollment

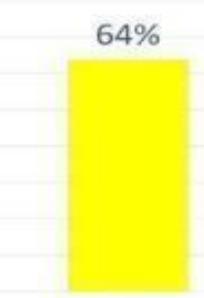

Maternity Leave

Type of inquiry
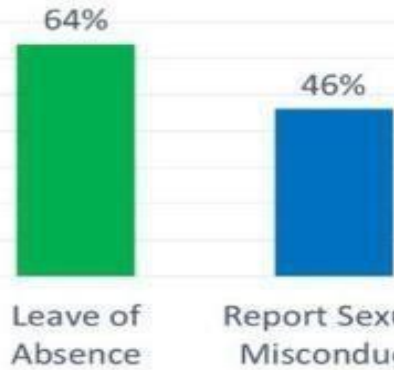

Report Sexual Misconduct

According to Deepak Bhardwaj, Service Now, general manager of company HR product line "by 2020 , based on using both in our personal life, I can see the penetration rate is as high as $75 \%$ in the workplace, employees can be solved by bot common human resources issues, and anytime, anywhere access to human resources solutions. Bharadwaj points out that considering the session the rapid development of artificial intelligence technology and the use of ease of use, we as the consumer behavior change how fast. Alexa amazon, for example, now has more than 15000 "skills" (amazon's voice applications), almost all of these are open to the outside developers in the Amazon Alexa after two years to create. In fact, since the fourth quarter of 2016, has created 10000 Alexa skills. When we adopt the bot in our daily life, we would expect to use bot in the workplace. There have been more and more technology companies with artificial intelligence solution (Textio), interview (Montagefalent), new employee training (Talla), training (mobile Coach), social acceptance (growBot) and employee service center. (service now) as the goal.

TECH I CHART OF THE DAY

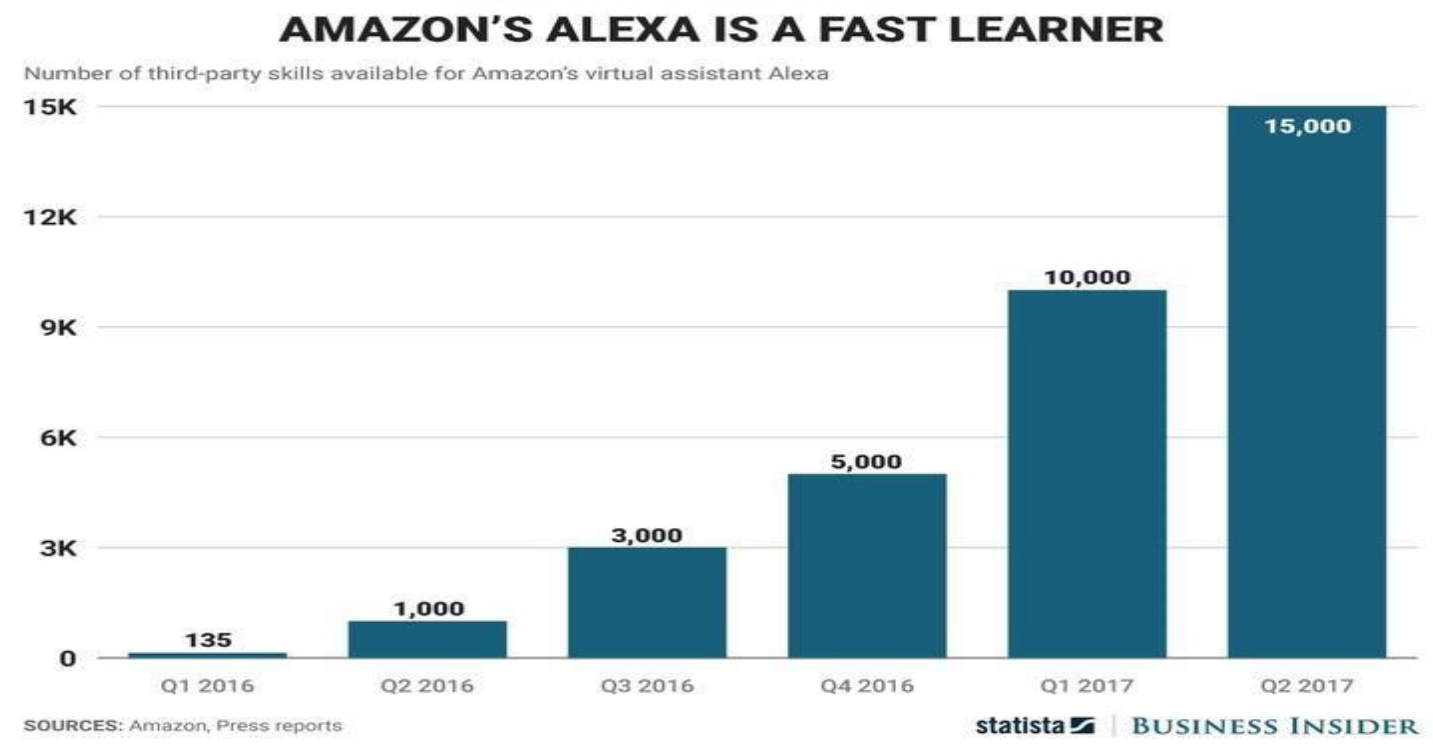




\section{HR at Capital Group: A Digital Transformation Journey}

Innovative experience for work applicants and employers is artificial intelligence and the bot. "The technology is for our clients to have world class advisors and investors to learn," said Diana Wong, Senior Vice President, Human Ressources. We would also assume that human resources with the use of artificial intelligence across the levels, from recruiting to on-the-job staffing and personnel development, represent the best classroom experience. In the human resources sector, Capital Group is testing some of the technology in artificial intelligence. The most powerful work description, without prejudice to the usage of Textio, is focused on the prediction interpretation of the Montage Talent Web-based video interview. In Wong's opinion, the guidance and usage of artificial intelligence not only enhances workforce productivity and efficiency, but also makes it possible for Capital Group to be seen as a new employer of millennial workers. However, there are several hurdles in the process of the human resources experiment of artificial intelligence. I was in Milan last week and told the tale of the power of artificial intelligence by a panel of senior personnel managers. The team discovered that using artificial intelligence in the area of challenges to human capital, the loss of the staff members was working with anxiety, lack of actual support for these emerging technological capacities, and new approaches to identify, hire and recruit workers to improve management. Wong emphasized that "one of the main success drivers in human resources is the use of artificial intelligence around transformation, the constant orientation of employee contact culture, and the digitization of how and why of human resources." When managers of human resources begin to develop the artificial intelligence plan and roadmap, the digital migration will start with five jobs. 1: Adopt artificial intelligence in our everyday lives as users by experimenting with a number of catboats, and now they're on the job. Try to introduce a high productivity bot to the HR team instead of just translating them. Some latest virtual robotic helpers, including Amy, Zoom and Shae, exist. Each illustrates the use of natural language processing to organize gatherings, automatically generate records and offer you a fresh way of accessing personalized health data. But why not play with these in your HR Department to understand more about AI's effect on behavior change?

2: Creating a shared mission for cross-functional partners HR, IT, Real Estate, Community and Digital Transformation. Providing compelling employee experience is a strategic benefit when it comes to hiring and retaining expertise. The companies realize that the experience of changing workers is not a strategy for human capital, but a business practice. This suggests that a standard approach is needed to digitally turn human capital, IT, immovables and organizational communications such as senior management In the short, medium and long term, shared view, workers experience how unforgettable and dramatic they are and determine the elements of seasoned employees.

3: Recognize the implications of the implementation of the application roadmap. Based on new technologies, such as the usage of artificial intelligence, a technological roadmap and a summary of short-term and long-term expectations and how these targets will be met, are essential. This suggests that cross-functional teams' human resources, IT and digital innovation need to agree on their employee's perspective and identify the technological path to do that. 
4: Identify new positions and use AI in HR entirely The addition of new workers in an organisation is part of the change experience phase. This expertise in establishing the position of director of employees. The first manager of Forbes column marc levy, an opportunity for employees "as a job experience: three new positions in human resources. What kind of organization would "New Standard" be to have, grow and recruit employees? McKinsey (McKinsey) has built a "modern standard" (new normal) over seven years; the word applies to industry in the area of fundamental transition following the 2008 crisis.

\section{The New Focus On the Employee Experience}

The Department of Human Resources creates a memorable atmosphere for the staff to redefine the "fresh standard" at work. Cooperation with the real estate manager, room planning, intelligence technology for work and an emotional relationship with workers at work. The growth of mobile technologies and the on-demand economy leads workers to a similar background of personal life and jobs, in both ages. As a sort of experience, the office becomes the highest concern of HR executives, who have written a column in particular, emphasize CHRO This illustrates the value of an employee, Mark Levy, how to amend his title as CEO. From GE Digital to IBM and Forrester firms, the benefit offerings in human resources are repensed and the customer mindset focuses on options for human resources. This suggests that the human resources group has data collection, design thinking and agile processes. People also ask: how does the organization build the workplace as a kind of experience? My response is that the prospective department of human resources takes a new position in managing the job. In three classes, I share three positions in human resources and have a lens, let us know about the changes in human resources to make the organisation's value more valuable.

\section{Three New HR Roles That Will Help You Create A Great Employee Experience Scrum Master Recruiting}

In rugger, scrum is the abbreviation of scrummage, refers to a way to start a game, in this case, the players would put their heads together tightly, and try to obtain the ownership of the ball. Similarly, the Scrum approach is also the core of the agile recruitment mode. This model includes the scrum approach used in software development, injection rate in the process of recruitment and management of unpredictability.GE Digital director of global talent acquisition Amber Grewal said: "GE Digital number of employees of international companies grown from 2012 in 100 to 2016 in 20000. Recruitment digital talent has always been one of the focuses of the company, in the process, we use some flexible software development methods, at the right time to get the right people at the right place." Ability to quickly perform to high growth firms is the key to success. As LinkedIn LNKD + 0\% Reid Hoffman, the founder of Hoffmann (Reid) in the Harvard Business Review (Harvard Business Review) in an article said, "when you need to rapid growth, expansion of lightning is what you want to do. Mortality rates will become the focus of a focus on" When you are in a whirlwind, some process inevitably will be broken. You can't handle them at the same time, you have to be classified. This mindset is now applied to recruiting talent for companies of fast development. For example, GE Digital created a modern agile recruiting platform and established its role as recruitment scrum master in order to meet its recruitment needs. This current position would include several scrum strategies used in product production and the most important 
customer to cope with problems across a wide range of recruitment criteria in slow, iterative measures. Recruiters should deliver expertise demands within two to six weeks and company targets in the day-to-day screenings rather than an average of 10-15 weeks. The recruitment scrum master also supports the scrum team (RST) and supports its employees (business) owner through continual changes and realization of the scrum method to optimize the performance. This way, digital recruiters and passive talents will come into touch and utilize the technologies of a hacker to locate applicants, contribute to the open source code or engage with them by gaming. As an applicant enters the digital talent community, recruiters will stay in contact with them to supply the organization with a good nominee in record time. He was able to cut recruiting time by $70 \%$ in software engineering and business software distribution. Scrum's recruiting procedure constraints, the job success in exchange, improve applicants' productivity, reduce the hiring period. Grewal predictions, such as data analyst recruitment and recruitment user design, would soon be able to penetrate the recruitment phase.

\section{People Analytics Director}

Watson became a celebrity after defeating two champions in a video game in 2011. Involvement in the adventure! Watson's natural language processing ability has been confirmed to be competitive with people's understanding abilities. The correct answer is given in response to the possibility of sorting. In 2016, IBM's HR capabilities include data mining, artificial intelligence, and natural language processing. "HR is fundamentally transformed into my huge amounts of data, and provide more detailed custom solutions for business," Diane Gerson said. Using the IBM patent (FU58600847 B1) + 0.03 percent has recently become one of the most interesting solutions. including risk forecast the key role of talent retention ability. Each year, IBM will check risk factors, such as position, salary, employee engagement, and even the overall level of a country and jobs. And then is Anshul Sheopuri, His team uses machine learning to measure the relative value of these and other variables while maintaining the privacy of the employees. The end result is that in the key positions and staff group, may be found outside of IBM opportunities, as well as a thoughtful manager intervention plan, in order to prevent the departure. It is reported that the move for IBM saves about $\$ 130$ million, in order to avoid the inevitable cost of hiring and training replacement staff. At present. Hundreds of IBM data scientist (is this example), director of the analysis data, to determine the active retention method and explore to recruit and hire the best way to IBM employees. One example is the manager's guide manuals, potential employees' job burnout, to remind managers or employees who found a late, and the employees should be guidance meeting or career development, in order to improve their promotion skills. Some also devoted to the analysis of internal social collaboration platform staff, the goal is to recommend company the method to solve the problem. Last year, People Analytics group reminded Gerson and her HR team on the platform of IBM Connections were widely discussed. For security reasons, IBM decided not to repay Uber Lyft a taxi and other services. However, Watson consulting firm based in New York (Watson consulting unit) of the new staff in one thousand Max (Max Black) proposed a Black argument, that is why in a group called "Global petition" IBM (IBM Global petition) internal blog, this policy should be revoked, to restore its repayment to carpool. Hundreds of thousands of people are involved. "The personnel analysis group" (People Analytics team) found these concerns, within 24 hours, Gerson changed the policy through its own blog. This makes the employee feel got to listen and solve their concerns. 


\section{Head of Employee Experience}

If there is no a real role: employees experience, director of HR to employee's experience transformation is incomplete. The role of in Forrester, reporting to the chief executive, and will be the center of the employees in the workplace. In Forrester, chief personnel officer Lucia Quinn thinks, create a compelling employees experience need to employees' needs and expectations have a profound understanding. This creates a new role, that is, head of the experience of the staff who is in charge of outside the scope of work of various departments, and human resources, real estate, marketing, IT and cross-functional role of internal communication, etc. We can assume that this title is Marc levy on reality, as I described in Forbes column, a CHRO became the chief staff officer, or create a new role, reporting to the chief personnel officer, like Forrest. In this new role for the forest, focus on creating a formidable employees experience, so the new staff will continue to work in the first few years. Often, a study shows, new employees will leave in less than two years of time because they are of low efficiency of workflow. This is what employee's experience's role in the company. It is interesting to note that in the case of the Forrester, employees experience, head of the Jon Symons comes not from HR, but from the department. Simmons said he was accused of "in Forrest employees and Forrest brand establish an emotional connection between". "In this phase, Simmons from analysis work on a series of Glassdoor web projects on how to leverage and other employers ranking sites to improve brand experience in the employee development cycle to build great hires, new employees to long-term employees for life, and also pursue Forrester alumni to advocate the business employer brand," says Simmons. Since the human resource department is to turn the workplace into an environment, these three protagonists are based on developing a compelling employee experience, which is now a "modern standard." These new positions have highlighted the fact that HR personnel have links to other fields, such as marketing communications, information innovation, and science data, and that these individuals are performing these functions. This is not only a new training of human resources, and is a human resource recruiting new skills! This role is responsible for all the life belongs to the life of someone whose work tasks by creating memorable experience span space, the development of recruitment, volunteer experience, even all aspects of Airbnb facilities on the menu. In the process of implementation staff experience conversion, I see other characters including Capital One session design leader, which is designed to create dialogue interface for the customer, in order to gain access to account records and perform financial transactions

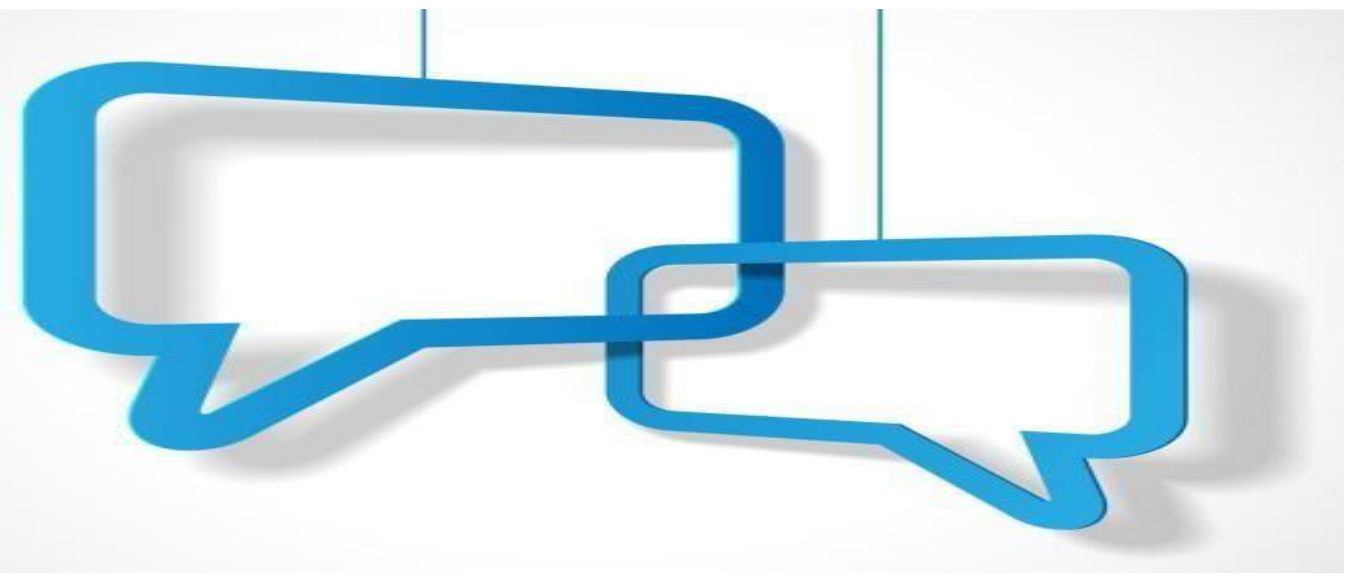


Steph Hay, Chairman of Capital One's Chat Management Group, acknowledges that her workto create user applications to access purchase information and complete financial tasks-is counterintuitive. Many people don't like talking to anyone about money, let alone using a voice or a computer. On the other side, Capita One launched last year's Alexa capability to enable customers to do as follows: Talks with Amazon to track expenditure, check accounts and pay bills. Alexa I sit down and talk to Hay Alexa and her colleagues on how we care about money in mind. Unlike most applications, consumers who use text or voice to connect with customers' financial products must work to build their confidence. "The pure difficulty of architecture is to find a natural language that encourages people to believe that we have their support. "Because we've had," said the shore. Hay's team concentrated on a few core principles to achieve this confidence: pleasing, not sarcastic, atomic architecture, first answering the concerns of clients and leading humanity. He also provided a special position for Scrum. This task is a huge amount of scrum methodology in software production. In such phases, the recruiting manager is the most valuable management obstacle, through a variety of employment criteria in gradual and iterative stages.

\section{Educate HR staff about the value of artificial intelligence in the workplace}

Set up a specialized information of $\mathrm{Al}$ in the team to influence how HR works. Designate a team member to work for the IT and digital conversion department, as well as HR, and have the most up-to-date insights on emerging technologies, programs, and companies in other fields such as communications or IT, to improve the consumer experience. AI use in the workplace is also in its early stages. but the development of $\mathrm{Al}$, its ecosystem, and add new specific understanding of the influence of the human resources work opportunity is enormous. We are just in artificial intelligence and bot changed all aspects of the human resource flow the beginning of the journey. Your company is how to use artificial intelligence to change the employee's experience?

\section{Artificial intelligence (AI) may be seen in five different forms in human capital}

In the last two decades, the advancement of information technology has had a substantial impact on human resources (HR). Artificial Intelligence (AI) is now reshaping the way businesses handle their employees and make HR schedules, resulting in increased efficiency and overall employee participation. Given that employee participation services increase sales by $26 \%$, it's obvious that you can embrace AI technologies to improve the squad and reap long-term benefits. We'll show you five ways to use AI in human resources management in this post.

\section{How Will Artificial Intelligence Support Human Resources}

Artificial intelligence (AI) has the potential to elevate your HR experience. As Donald Southern, a resume expert at Resume World, put it: “AI can help you to handle recruiting, productivity, and retention more efficiently than traditional HR methods. At the same time, it also allows you to do it faster than ever before." Let's see here exactly how AI is doing that.

Talent Acquisition: You will save the HR supervisors a lot of time and effort by implementing AI. Specifically, talent management tools will search, translate, and review candidates, removing $75 \%$ of the time spent in the recruitment phase. This is a significant advantage since it helps the 
recruiter to devote more effort to reviewing and interviewing a limited number of qualified applicants. HR departments are significantly improving the consistency of recruiting choices in such situations. Furthermore, businesses save a lot of money because they don't have to compensate for the consequences of bad recruiting choices.

Onboarding: Hiring HR agencies are concerned with more than just the most talented talents. The second stage in the process is adaptation, when many prospects will struggle to adjust to their current surroundings owing to a lack of onboarding procedures. New workers, in particular, necessitate a great deal of commitment, and it is always impractical to devote adequate time to each of them. That's where AI comes in: it creates personalized onboarding protocols for each position. In fact, this appeared to be highly beneficial, since prospective employees who went through well-planned onboarding systems reported significantly better retention rates than those who did not.

Training: With too many technical advancements occurring almost monthly, it is important for all workers to continue to develop and develop their professional skills. AI will schedule, arrange, and manage training activities with all members of the team. The most popular options in this regard are online classes and remote classrooms. However, AI does more than that; it also decides the best timetable for new classes and plans lessons to meet the particular needs of all workers.

Performance analysis: Good practitioners must have high levels of engagement and efficiency. However, several businesses are having difficulty finding people that possess certain characteristics. As a result, it's also simpler to keep track of their behavior and assess important success metrics. HR administrators may use AI software to establish concrete goals and have all departments run in smaller intervals. This style of work is simpler to follow and evaluate, and the final outcomes are higher. Of course, it isn't only about increasing productivity; it may even be used to identify team participants that are consistently disengaged.

$\square$ Retention: It's tough to find and retain great people, and it's much more difficult to keep them on the staff. This is why almost $60 \%$ of businesses perceive job engagement to be their most serious issue. AI, on the other hand, will evaluate and forecast the desires of employees. It will identify human affinities and show who can be promoted or who is unhappy with their work-life balance. This kind of research allows HR practitioners to be constructive to fix problems before they emerge.

\section{CONCLUSION}

These days, AI can be used in anything from basic calculators to flight controls and space operations. It also helps HR executives to maximize performance and more effectively track staff. We discussed five ways to use AI in human resources in this post. Be sure to put these tips to good use in your daily company and let us know what you think in the comments.

\section{References}

[1] Winston, P. H. Artificial Intelligence. Third Edition, Addison-Wesley Publishing Company, 1992. 
[2] Fogel, D. B. Defining Artificial Intelligence. In Evolutionary Computation: Toward a New Philosophy of Machine

[3] Intelligence. Third Edition. The Institute of Electrical and Electronics Engineers, Inc., IEEE Press, 2006.

[4] Legg, S. and Hutter, M. Universal Intelligence: A Definition of Machine Intelligence. Minds and Machines, 17(4):391-444, Springer, 2007.

[5]. McCarthy, J. and Stanford University Formal Reasoning Group. What Is Artificial Intelligence | Basic Questions, Formal Reasoning Group, 2007 (Last accessed: June 18, 2017).

[6] Wang, P. What Do You Mean by “AI”? In P. Wang, B. Gentzel, and S. Franklin (eds.), Artificial General Intelligence 2008, Proceedings of the First AGI Conference, Frontiers in Artificial Intelligence and Applications, 171:362-373. IOS Press Amsterdam, The Netherlands, 2008.

[7]. Laird, J. E., Wray, R. E., Marini, R. P., and Langley, P. Claims, and Challenges in Evaluating Human-Level Intelligent Systems. In B. Gentzel, P. Hitler, \& M. Hutter (eds.), Proceedings of the Second Conference on Artificial General Intelligence. Atlantis Press, 2009.

[8] Gentzel, B. Toward a Formal Characterization of Real-World General Intelligence. In E. B. Baum, M. Hutter, and E. Kitzelmann (eds.), Artificial General Intelligence, Proceedings of the Third Conference on Artificial General Intelligence, AGI 2010,

[9] Lugano, Switzerland, March 5-8, 2010, pp. 19-24. Advances in Intelligent Systems Research 10. Amsterdam: Atlantis, 2010.

[10] Nilsson, N. J. The Quest for Artificial Intelligence. A History of Ideas and Achievements. Cambridge University Press, 2010.

[11] Russell, S. J., and Norvig, P. Artificial Intelligence: A Modern Approach, Third Edition. Prentice Hall, 2010.

[12] Muehlhauser, L. and Salmon, A. Intelligence Explosion: Evidence and Import. In A. H. Eden, J. H. Moor, J. H. Soraker, and E. Steinhart (eds.), A Scientific and Philosophical Assessment (pp. 15-42), Springer, 2012.

[13] Bostrom, N. Superintelligence. Paths, Dangers, Strategy. Oxford University Press, 2014. 
[14] Gershman, S. J., Horvitz, E. J., and Tenenbaum, J. B. Computational rationality: A converging paradigm for intelligence in brains, minds, and machines. Science 349(6245):273-278, 2015.

[15] Mnih, V. et al. Human-level control through deep reinforcement learning. Nature, 518:529-541, Macmillan Publishers Limited, 2015.

[16] Ema, et al. Future Relations between Humans and Artificial Intelligence: A Stakeholder Opinion Survey in Japan. IEEE Technology and Society Magazine, 35(4):6875, December 2016.

[17] The United States Defense Science Board (DSB). Defense Science Board Summer Study on Autonomy. Publisher: United States. Defense Science Board, 2016. Retrieved from https://goo.gl/mm6N6y, last accessed: June 21, 2017.

[18] De Spiegeleire, S., Maas, M., and Sweijs, T. Artificial Intelligence and the Future of Defense: Strategic Implications for Small and Medium Sized Force Providers.The Hague Centre for Strategic Studies, 2017.

[19] Lewis, C. W. P. and Monett, D. A Theory of Understanding Human Intelligence and a Persuasive Definition of Machine Intelligence for the Benefits of Humanity. (Working paper, unpublished)

[20] Ebbinghaus, H. Psychology: An Elementary Textbook. M. F. Meyer (Ed.). Boston: Heath, 1908.

[21] Binet, A. and Simon, T. The development of intelligence in children (the Binet-Simon scale). In H. H. Goodard (Ed.), The development of intelligence in children. Baltimore: Williams \& Wilkins (original work published 1909, republished 1916).

[22] Wechsler, D. The measurement of adult intelligence. Baltimore: Williams \& Wilkins, 1939.

[23] Bigge, M. L. Learning Theories for Teachers. Third Edition, London: Harper \& Row Publishing, 1976.

[24] Humphreys, L. G. General Intelligence. In C. R. Reynolds and R. T. Brown (eds.), Perspectives on bias in mental testing, Springer, 1984.

[25] Anastasi, A. Intelligence as a quality of behavior. In R. J. Sternberg and D. K. Detterman (eds.), What is intelligence? Contemporary viewpoints on its nature and definition (pp. 19-21). Norwood, NJ: Ablex, 1986. 
[26] Das, J. P. On the definition of intelligence. In R. J. Sternberg and D. K. Detterman (eds.), What is intelligence? Contemporary viewpoints on its nature and definition (pp. 55-56). Norwood, NJ: Ablex, 1986.

[27] Sternberg, R. J. Intelligence is mental self- government. In R. J. Sternberg and D. K. Detterman (eds.), What is intelligence? Contemporary viewpoints on its nature and definition (pp. 141-148). Norwood, N.J: Ablex, 1986.

[28] Fontana, D. Psychology for Teachers. Second Edition, London: Macmillan, 1988.

[29] Gottfredson, L. S. Mainstream science on intelligence: An editorial with 52 signatories, history, and bibliography. Intelligence, 24:13- 23, 1997.

[30] Ramos-Ford, V. and Gardner, H. Giftedness from a multiple intelligences perspective. In N. Colangelo and G. A. Davis (eds.), Handbook of gifted education. Second edition (pp. 439-459). Boston: Allyn \& Bacon, 1997.

[31] Simonton, D. K. Defining Intelligence [Streaming Video]. The Trustees of Indiana University, 2003. Retrieved from http://www.indiana.edu, last accessed: June 28, 2017.

[32] Sternberg, R. J. The Theory of Successful Intelligence. Journal of Psychology, 39(2):189-202, 2005.

[33] Deary, I. J., Penke, L., and Johnson, W. The neuroscience of human intelligence differences. Nature Reviews, Neuroscience, 11:201- 211, March 2010.

[34] Hampshire, A. et al. Fractionating Human Intelligence. Neuron 76:1225-1237. Cell Press, Elsevier Inc., December 2012.

[35] Stanovich, K. E. Assessing Cognitive Abilities: Intelligence and More. Journal of Intelligence. 2(1):8-11, February 2014.

[36] Sneakers, S. et al. Genome-wide association meta-analysis of 78,308 individuals identifies new loci and genes influencing human intelligence. Nature Genetics (pp. 1-8), 2017.

[37] Meister, Jeanne. “According to Facebook Vice President, David Marcus, There Are Now More than 100,000 Chatbots on the Facebook Messenger Platform, up from 33,000 in

2016

[38] Chat Extensions: Facebook Turns to Discovery, Third-Party Chat Extensions in Latest Messenger Platform Push Ken Yeung@Thekenyeung April 18, 2017 
[39] Custom Integrations with Apps like Delivery.com.:

[40] Facebook Testing Third-Party M Integration in Messenger with Delivery.com Ken Yeung@Thekenyeung April 18, 2017

[41] Facebook Messenger Gets M AssistantPowered Suggested Responses Ken Yeung@Thekenyeung April 6, 2017

[42] Chatbots Digitize HR Processes and Enable Employees to Access HR Solutions from Anywhere. 2016

[43] Jeanne Meister, The Intersection of Artificial Intelligence and Human Resources: The Future Of Work: The Intersection Of Artificial Intelligence And Human Resources 2016

[44] Amazon Business Insider Intelligence Report: In Total, Alexa Is Touted as Having More than 3,000 Skills and Growing Daily Sep. 15, 2016,

[45] Amazon's Alexa Now Has More than 3,000 Skills Business Insider Intelligence Sep. 15, 2016,

[46] Twitter: Artificial Intelligence Is Not the Future of the Workplace, It Is the Present and Happening Today. \$1.5 Billion Being Invested in More than 200 AI-Focused Companies in 2016. :

[47] Twitter: Investors Are Backing More AI Startups than Ever before Sep. 15, 2016

[48] Twitter: HR Leaders Will Need to Begin Experimenting with All Facets of AI to Deliver Value to Their Organizations with 35 Million Enrolled MOOC Enrolment Surpassed

35 Million in 20155 Jan 2016

[49] Amazon's Alexa Now Has More than 15,000 'Skills': Amazon's Alexa Has Gained 14,000 Skills in the Last Year Jeff Dunn Jul. 5, 2017

[50] McKinsey report The Workplace as An Experience: Three New HR Roles Emerge, Jeanne Meister, Seven Years since Coined the Phrase 'the New Normal,' March 2009:

[51] McKinsey Quarterly The New Normal Commentary March 2009 Ian Davis How 
Airbnb CHRO Mark Levy Changed His Job Title to Chief Employee Experience Officer:

Airbnb CHRO Becomes Chief Employee Experience Officer: March 2009

[52] Jeanne Meister: The Future Of Work: Airbnb CHRO Becomes Chief Employee Experience Officer Research Shows New Employees with Tenure of Fewer than Two Years Leave Because of Frustration： : March 2009

[53] Jeanne Meister: Do You Have a Chief Employee Experience Officer (CEO) Leading Your Digital Workplace? By Ephraim Freed Create Conversational Interfaces for Customers to Access Account Information and Complete Financial Tasks. : March 2009

[54] Jeanne Meister: Recruiting Scrum Master.: Conversation Design Is the next Big UX Challenge for Capital One Jessica Collier, All Turtles@ Verbagetruck February 24, 2017

[55] HR Service Delivery: Boost Company Top HR Statistics The Latest Stats for HR \& Recruiting Pros February 24, 2017

[56] Forbes Magazine, Human Resources Fun Facts \& Serious Statistics Posted on May 21, 2015

[57] Forbes Magazine, Aking Much Higher Retention Rates: 9 Surprising Employee Onboarding Statistics 60\% of Organizations : HR Statistics for Human Resource Management." 19 Jan. 2018, 